\title{
Income Inequality among Various Occupations/Professions in Pakistan-Estimates Based on Household Income Per Capita
}

\author{
Mehboob Ahmad*
}

\section{Introduction}

There is a long list of studies related to distribution of income in Pakistan. Most of these have been confined to the calculation of various measures of inequalities. These studies include Khadija Haq (1964), Bergan (1967) Mehmood (1984), Ercelawn (1988), Ahmad and Ludlow (1969) etc. Apart from these there are other studies including Jeetun(1978), Chaudhry (1982), Cheema and Malik (1984) Kruijk and Leeuwen (1985), Kruijk (1986), Kemal (1994), Jaffery and Khattak (1995), Chaudhary (1995) etc. Jeetun (1978) in his paper concentrated on consequences of economic growth on the level of inequality whereas Chaudhary (1982) tried to find out the impact of the Green Revolution on income inequalities. Cheema and Malik (1984) tried to find out the effects of different income policies on the consumption and level of employment in Pakistan. Kemal (1994) examined the impact of the adjustment period of Pakistan since the late 1970s on efficiency and equity. Jaffrey and Khattak, while utilising HIES 1990/91, measured and analysed inequality and poverty in Pakistan together with their historical trends. They also analysed the phenomenon of income inequality and poverty and their relation to the distribution of assets and employment. Chaudhary (1995) computed and analysed income inequality in Pakistan as well as in its provinces broken down to rural urban level. He not only studied the extent of inequality in Pakistan but also its change over time measured on the basis of per capita income distribution involving households.

In spite of the existence of such a long list of studies related to distribution of income in Pakistan, very little attempt has been made to study the income inequalities between and within various occupations/ professions in Pakistan. Exceptions to this are studies by Kruijk and Leeuwen (1985) and Kruijk (1986). Kruijk and Leeuwen (1985) examined the incidence of poverty and inequality in Pakistan in 1975 and also decomposed the measure of inequality into various components. This was done to identify the location, the magnitude and the changes of various inequalities etc. They decomposed Theil's measure of inequality (T) into

\footnotetext{
*Assistant Professor, Dept. of Economics, Allama Iqbal Open University, Islamabad.
} 
two parts: The explained part (or the between component) and the unexplained part (or the within component). Accordingly they decomposed overall $\mathrm{T}$ into inequalities within and between urban and rural areas. In this way $T$ was decomposed into inequality which is attributable to inequality between urban and rural areas and (i) inequality within urban areas and (ii) inequality within rural areas. Then urban areas and rural areas inequalities are further decomposed into earners and number of earners per household. In the third step, inequality among earners is decomposed into inequality between occupational groups and inequality within occupational groups. This exercise is done for the two time periods that is for $1969 / 70$ and 1979.

In this paper we have adapted a different approach to that of Kruijk and Leeuwen (1985) and Kruijk (1986). Instead of decomposing Theil into various components and then finding inequality between and within occupations, we have calculated the Gini coefficient for each occupational group. Once we were able to calculate Gini coefficients for each occupation/profession there was no problem in comparing the level of inequality among various professions or occupations.

\section{Data Base}

The main feature of this study is that it is based on individual household data of the Household Integrated Economic Survey (HIES) 199293 being conducted by the Federal Bureau of Statistics. At the time of this study the Household Integrated Economic Survey 1992-93 was the latest data available on tapes. The universe of this survey consists of all urban and rural areas of the four provinces of Pakistan defined as such by the 1981 Population Census excluding FATA, military restricted areas, districts of Kohistan, Chitral, Malakand (Protected Area) and PATA of NWFP. The population of excluded areas constitutes about 4 per cent of the total population.

\section{Sample Covered}

Due to various reasons, of 14,976 households, 382 households could not be numerated for various reasons such as non-contact, locked house etc.. Thus the results of this survey are based on 14,594 households.

\section{Package Used}

The package used to calculate measures of inequality is the Statistical Package for Social Sciences (SPSS). 


\section{Frame of Reference}

The utility and soundness of any exercise relating to estimating and analysing income inequalities not only depends on the choice of the package of inequality indices but also on the choice of some appropriate income receiving/consuming unit(s). The most commonly used income receiving/ consuming unit (frame of reference) is the household but according to Kuznets (1976) "it makes little sense to talk about inequality in the distribution of income among families or households by income per family or household when underlying units differ so much in size. A large income for a large family may turn out to be small on per person or per consumer equivalent basis, and a small income for a small family may turn out to be large with allowance for the size of the family. It follows that before any analysis can be undertaken size distributions of families or households by income per family or household must be converted to distribution of persons (or consumer equivalents) by size of family or household income per person or per consumer" (Kuznets. 1976/87).

The point is that there is no sense in assigning equal weights to a single person household and a household consisting of say ten or more members. The traditional framework which treats households as equal units regardless of their size and composition grossly distorts the true image of the distribution of income and makes the level of inequality look like what it really is not. Similarly, any inter-temporal comparison of pattern and trend of inequalities may give misleading directions if analysis of income distribution is conducted in terms of per household/family income. In reality "trends observed in the conventional distribution may well be associated with trends in size differences among families, not in income per person or per consumer" (Kuznets, 1976).

In view of the above arguments, an attempt is made to calculate the Gini coefficient as a measure of inequality using individuals as the frame of reference. Gini coefficient can be computed using the following formula:

$$
\mathrm{G}=1-\sum_{i=1}^{n} \operatorname{Spi}\left(Y i+Y i_{-1}\right)
$$

Where $S_{p i}$ is the population share of the ith income group and $Y_{i}$ is the cumulated income share of the ith income group.

As mentioned above, in our study, instead of households, persons have been used as the frame of reference. This has been done by replacing 
Cases (households) column with Sum (population numbers) column in the SPSS programme.

Ours is not the first attempt in this direction. A number of other writers have calculated various measures of inequalities for countries of their choice using both households and individuals as the frame of reference. These include Kuznets $(1963,1976)$, Ranadive (1965), Ojha (1971), Kumar (1974), Henry (1975), Hsia and Chou (1978), Visaria (1980), Datta and Meerman (1980), Choudhry $(1982,1984,1995)$ and many others.

\section{Level of Inequality in Various Occupations/Professions}

Before discussing levels of inequality among various professions/ occupations in Pakistan, it is probably more appropriate to define various occupations or professions in the first place. For this study we have defined occupations in accordance with the Pakistan Standard Classification of Occupations (1994) as published by the Bureau of Statistics. The Pakistan Standard Classification of Occupations 1994 divides various occupations or professions into Major, Sub-Major and Minor groups. Following Pakistan Standard Classification we have divided our occupations into six Majors compared with nine Majors of Pakistan Standard Classification. In our case we have categorised together some occupations for our convenience and also because it made economic sense. In the slightly modified classification (in our table), the last three Majors could be interpreted as White Collar Workers, Skilled Workers, and Unskilled Workers. That is why we have classified our occupations into the following six Majors, as may be seen from Tables- 1 and 2 and also from the table below.

(i) Legislators, Senior Officials and Managers include

- Legislators and Senior Officials, Corporate Managers and General Managers

(ii) Professionals include

- Physical, Mathematical and

- Physical, Mathematical and Engineering Science Professionals

- Life Science and Health Professionals

- Teaching Professionals

- Other Professionals 
(iii) Technicians and Associate Professionals include

- Physical and Engineering Science Professionals

- Life Science and Health Associate Professionals

- Teaching Associate Professionals

- Other Associate Professionals

(iv) Clerks, Service Workers and Shop and Market Sales Workers include

- Office Clerks

- Customers Services Clerk

- Personal and Protective Services Workers

- Models, Sales Persons and Demonstrators

(v) Skilled Agricultural, Fishing, Craft and Related Trade Workers, Plant and Machine Operators and Assemblers include

- Market-Oriented Skilled Agricultural and Fishing Workers

- Subsistence Agricultural and Fishing Workers

- Extraction and Building Trade Workers

- Precision, Handicrafts, Painting and Related Trades Workers

- Other Craft and Related Trades Workers.

- Stationary-Plant Related Operators

- Machine Operators and Assemblers

- Drivers and Mobile Plant Operators

(vi) Unskilled Labour, Elementary Occupations include

- Sales and Services Elementary Occupations

- Agricultural, Fishing and Related Labour.

- Labour in Mixing, Construction, Manufacturing and Transport. 
While looking at the list of Gini coefficients against various occupations for all Pakistan in sub-table 1(a) \{in Table 1\}, we can see that the highest level of inequality (Gini coefficient) is recorded by skilled workers i.e. by skilled agricultural, fisheries, craft and related trade workers plus plant and machine operators and assemblers. The Gini coefficient for these skilled workers is 0.299 . This figure is higher than 0.291 calculated for all Pakistan, by the author ${ }^{1}$, elsewhere. One of the probable reasons for this high figure is that in the category of skilled workers a diverse bunch of workers are included varying from market oriented gardeners to subsistence agricultural workers, mines to precision metal workers, plant operators to ship deck workers. Even though they are all skilled workers, their incomes or earnings are quite diverse. For example, heavy machine operators earn much more than skilled but subsistence agriculture or fishery workers. Similarly, skilled extraction workers earn much more than just drivers. That is why when such diverse workers are brought together under the umbrella of skilled workers this high level of the Gini coefficient (therefore, inequality) is no surprise.

The second highest Gini coefficient is shown by the first occupation in our table, that is the legislators, senior officials and managers (Gini=0.273). In this group again the high figure of the Gini coefficient probably reflects the different kinds of people grouped together in one occupation or professional group. In this category we have all sorts of people including legislators (mostly landlords and industrialists), senior government officials, directors and chief executives of government/semi government and private organisations. All the people who fall into this category/group are high earning people. Most of the legislators have a landed or industrial back ground. Those who are not very rich become rich once they enter parliament. But still there are some parliamentarians who are not rich but also not corrupt. That is why some diversity in income level is observed through a moderately high value of the Gini coefficient. There is however, diversity of incomes among different senior officials. Some of the senior officials with specialised skill get much higher salaries than the ordinary senior government officials. Corruption is one way by which many senior officials try to equalise their incomes with their highly skilled counterparts. But still there is no dearth of honest senior officials whose incomes are much lower than their skilled and corrupt counterparts. That is why we see

\footnotetext{
${ }^{1}$ Ahmad, Mehboob (2001) Distribution of Income in Muslim Countries vis-à-vis nonMuslim Countries (Unpublished Thesis, Bahauddin Zakria University,Multan).

See also in

Ahmad, Mehboob (2001) "Estimation of Distribution of Income in Pakistan Using ICRO Data" Paper Presented in $16^{\text {th }}$ AGM of the Pakistan Society of Development Economists Scheduled Held During January 22-24,2001 PIDE, Islamabad.
} 
a relatively high Gini coefficient for this apparently homogenous (income wise) group.

The professionals group that includes physical, mathematical and physical, mathematical and engineering science professionals, life science and health professionals, teaching professionals etc, show the lowest level of inequality in Pakistan (Gini=0.136). Even though this group includes various professionals, they are very uniform and homogenous in terms of levels of incomes. The homogeneity in terms of incomes among such diverse professionals is due to the fact that almost all the professionals included here are government employees and government pays in terms of a uniform grading system to all its professionals. There are some professionals (like doctors) whose incomes (apart from salary) are much higher than common professionals (like teachers). But such professionals are very few compared with the total number of professionals in Pakistan. That is why, in the author's view, we find a high degree of income uniformity in this group.

The second lowest inequality is seen among unskilled workers in Pakistan (Gini=0.180). High level of income equality among unskilled workers shows that their earnings level is the same no matter where they are employed and also that they are all poor.

The sub-table-1(b) shows the distribution of income among various professions/occupations in the province of Punjab. The pattern of distribution in Punjab is more or less the same as in all Pakistan with some minor exceptions. In the province of Punjab too the highest level of inequality is seen among skilled workers $(\mathrm{Gini}=0.307)$ followed by legislators, senior officials/managers $(\mathrm{Gini}=0.268)$ and clerks $(\mathrm{Gini}=0.250)$.In Punjab the fourth place is taken by unskilled workers(Gini=0.199) compared to associate professionals/technicians $(\mathrm{Gini}=0.217)$ in all Pakistan. The lowest level of inequality in Punjab is shown by professionals (Gini=0.108) and associate professionals/technicians $(\mathrm{Gini}=0.191)$. In the case of all Pakistan the second lowest position is taken by unskilled workers (Gini $=0.180$ ).

The sub-table 1(c) shows distribution of income among various professions in the province of Sindh. The pattern of Gini coefficients in Sindh is exactly the same as we observed in the case of the Punjab, even though almost all the Gini coefficients are lower than the Punjab. Here too the highest level of inequality is seen among skilled workers (Gini= .304) followed by legislators, senior officials/managers (Gini=.226) and clerks (Gini=.247). The lowest level of inequality in Sindh is seen among professionals $(G i n i=.105)$ followed by associate professionals/technicians (Gini=.188) and unskilled workers $(\mathrm{Gini}=.196)$. The difference between the 
patterns of inequalities between Sindh and Pakistan is the same as we observed in the case of the Punjab and Pakistan.

The sub-table-1(d) shows distribution of income among various professions in the province of N.W.F.P. The pattern of Gini coefficients in N.W.F.P. is exactly the same as we observed in the case of the Punjab, even though all the Gini coefficients are higher than the Punjab. Here too the highest level of inequality is seen among skilled workers (Gini= .314) followed by legislators, senior officials/managers (Gini=.277) and clerks (Gini=.258).The lowest level of inequality, in N.W.F.P., is seen among professionals (Gini=.116) followed by associate professionals/technicians (Gini=.199) and unskilled workers $(\mathrm{Gini}=.207)$. The difference between the patterns of inequalities between N.W.F.P. and Pakistan is the same as we observed in the case of the Punjab/Sindh and Pakistan.

The sub-table-1(e) shows distribution of income among various professions in the province of Balochistan. The pattern of Gini coefficients in Balochistan is exactly the same as we observed in the case of other provinces but the values of its Gini coefficients are much lower than the other four provinces. Here too the highest level of inequality is seen among skilled workers (Gini $=.295)$ followed by legislators, senior officials/managers $(\mathrm{Gini}=.257)$ and clerks $(\mathrm{Gini}=.240)$.The lowest level of inequality, is seen among professionals (Gini $=.096$ ) followed by associate professionals/technicians $(G i n i=.179)$ and unskilled workers $(G i n i=.188)$. The difference between the patterns of inequalities between Balochistan and Pakistan is the same as we observed in the case of Punjab and other provinces of Pakistan. Table 1 shows a certain degree of inequality among various professions in all Pakistan as well as in its provinces. But the inequality observed is not statistically significant as may be seen from low $\mathrm{F}^{*}$ values given at the end of Table 1 .

We can observe relative inequality among various occupations by rearranging the data in Table 1 \{sub-tables $1(\mathrm{a}), 1$ (b), 1 (c), 1 (d), 1 (e)\} into Table 1(1) \{sub-tables 1(aa), 1(bb) 1 (cc), 1 (dd) and 1 (ee)\}. In Table 1(1) \{subtables1 (aa) to 1 (ee)\} we have rearranged Gini coefficients from highest value to the lowest value. These relative inequalities are presented in the form of difference of Gini coefficients between the two occupations/ professions. This new data is presented in the fourth column of sub-table 1(aa) and third columns of sub-tables $1(\mathrm{bb})$ to $1(\mathrm{ee})$. For example, in sub-table $1(\mathrm{aa}), .026$ is the difference between Gini coefficients of skilled workers and clerks. Single entries are shown at the end of each sub-table \{last row of table 1(1)\}. These single entry figures show the level of relative inequality between the most equal profession/occupation and the least equal profession/occupation. For example, .163 is the difference between professionals and skilled workers in 
sub-table 1 (aa). The difference figures in column $3\{$ fourth in $1(\mathrm{aa})\}$ show that all professions/occupations show almost the same relative inequality in all the provinces of Pakistan including all Pakistan. Similarly, the same level of relative inequality is observed between highly equal profession/occupation (professionals) and the most unequal profession/occupation (skilled workers) in the four provinces of Pakistan, excluding all Pakistan. This phenomenon is observed despite the fact that different levels of inequality are seen among the provinces in any given profession/occupation. This uniform relative inequality has been established when we arranged the Gini coefficients from higher to lower level inequality professions/occupations.

We can gain even more insight when we further rearrange our data in terms of various professions/occupations. This is what we have done in Tables 2 (a) to 2 (f). In Table 2 (a) Gini coefficients for legislators/senior officials/managers is presented. The table shows that in terms of income inequality, the group of legislators, senior officials and senior managers is highly uniform and homogenous in all the four provinces of Pakistan. The Gini coefficient, only varying from 0.257 to 0.277 , is almost the same for all Pakistan as well as for the four provinces of Pakistan. This table also shows uniformity and homogeneity of the political, economic and administrative ruling classes in our country. In other words this is an indicator of the fact that the ruling class in Pakistan has the same socio-economic and family background. Nepotism is so strong that if one brother is a high government official (civil/military) then the other could be a legislator and yet another brother could be chairman of some big public or private business enterprise (see Amjad: 1977). This phenomenon is common in all developing countries including Pakistan. A slightly higher Gini coefficient is recorded by N.W.F.P. legislators/senior officials/managers compared with other provinces especially Balochistan. This could be safely attributed to chance. If however, the difference is real then in the N.W.F.P., there are some legislators/senior officials/managers who are making more money than their own colleagues in their own province. Lower value of Gini coefficient in Balochistan is an indicator of dominance of certain minority, uniform and homogenous class in all walks of life including economic, political, social etc.

Professional class in the four provinces of Pakistan including all Pakistan has shown a very low level of inequality among its ranks. Punjab (Gini=.108) and Sindh (Gini=.105) are very close to each other. In this group the highest level of inequality is observed among the professionals of all Pakistan and N.W.F.P., with Gini coefficients of .136 and .116 respectively whereas the lowest level of inequality is shown among Balochistan professionals with Gini coefficient of only .096. In terms of income inequality, the pattern of legislators is repeated among the 
professionals reflecting the fact that there is a very close relation between these classes in the sense that those people who are in the higher income bracket like legislators/senior officials, are closely related to professionals. This relationship could be in the form of kinship and /or economic/ political/social association (see Amjad: 1977).

Like professionals, technicians/associate professionals also show a very low level of inequality as may be seen from the low level of Gini coefficient in Table-2(c)) of associate professionals. Within this group the highest level of inequality is observed in all Pakistan (Gini=.217) and N.W.F.P. (Gini=.179) followed by the province of Punjab (Gini=.191). Whereas the lowest level of inequality is shown in Balochistan (Gini=.179) followed by Sindh $($ Gini=.188).

Income inequality among clerks [Table 2 (d)] is much higher then the earlier two groups. Within clerks the highest level of inequality is recorded by all Pakistan (Gini $=.265)$ and N.W.F.P. (Gini $=.258$ ) followed by the province of Punjab (Gini=.250). In line with the previous three occupations, Balochistan clerks also show the lowest level of inequality $(G i n i=.240)$ among its ranks. This indicates more or less equal opportunity to make money for clerks in this province.

Table-2 (e) shows the level of inequality among skilled workers in various provinces of Pakistan including all Pakistan. The table shows that the highest level of inequality among skilled workers is in the N.W.F.P. (Gini=.314) followed by the Punjab (Gini=.307). The lowest level of inequality, as before, is recorded by Balochistan workers (Gini=.295) followed by Sindh $($ Gini $=.304)$ and all Pakistan $(\mathrm{Gini}=.299)$. The pattern of inequality among the unskilled workers is the same as we observed in the cases of other professions /occupations. Here again the highest level of inequality is observed among N.W.F.P. unskilled workers (Gini=.207) followed by Punjab (Gini=.199) and highest level of equality is seen among Balochistan unskilled workers (Gini=.188) followed Sindh unskilled workers $(\mathrm{Gini}=.196)$. Table 2 shows the uniformity of various professions across the four provinces of Pakistan. This is reflected in the low value of $F^{*}$ written at the end of Table 2.The last row of the table shows that the moderate difference observed in the distribution of income across the provinces is not statistically significant.

What we can conclude from this section is that despite having substantial differences in income inequalities among various professions/ occupations, the pattern of income inequality is broadly similar among the various provinces of Pakistan. 


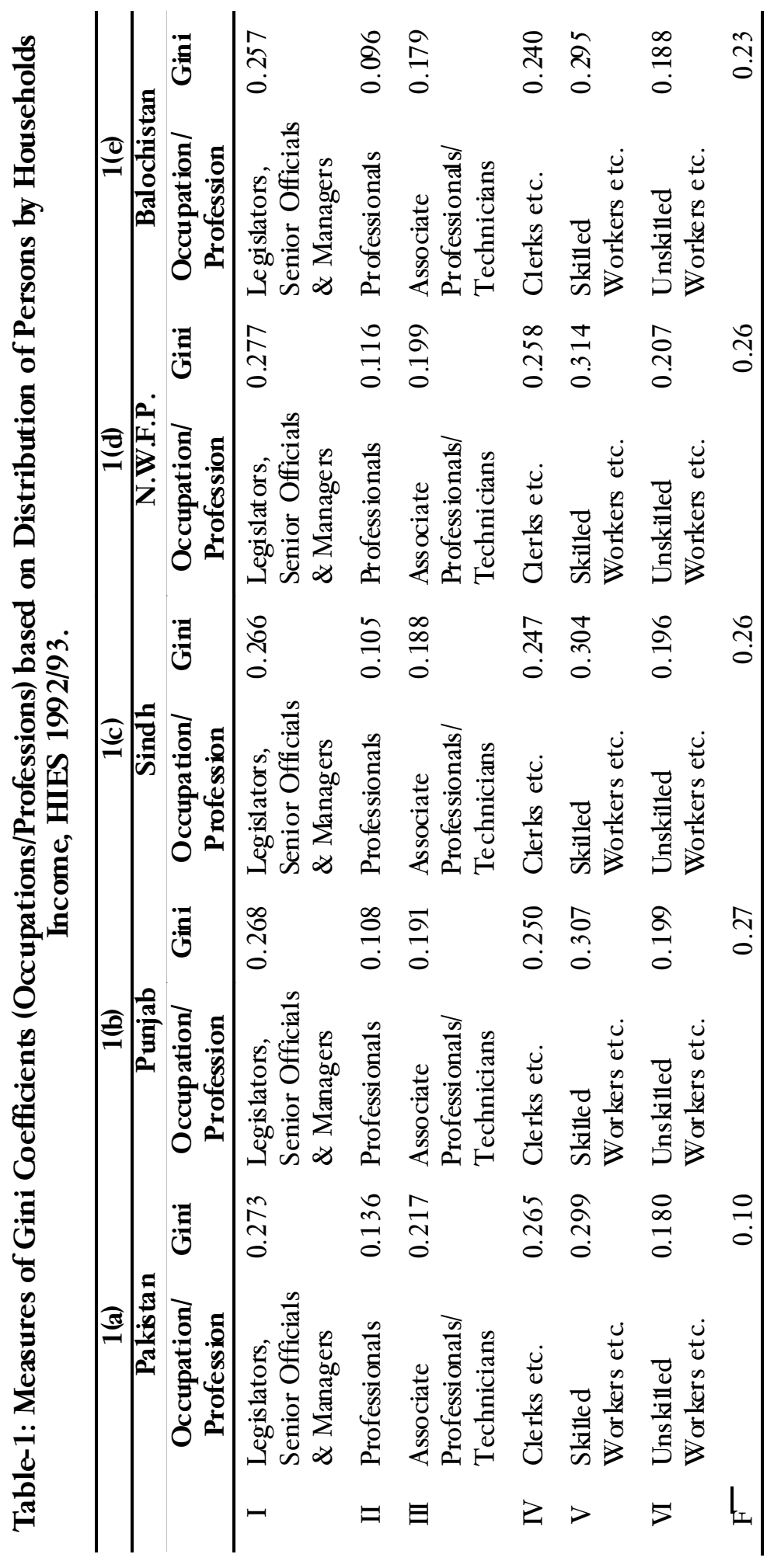


100 The Lahore Journal of Economics, Vol.7, No.1

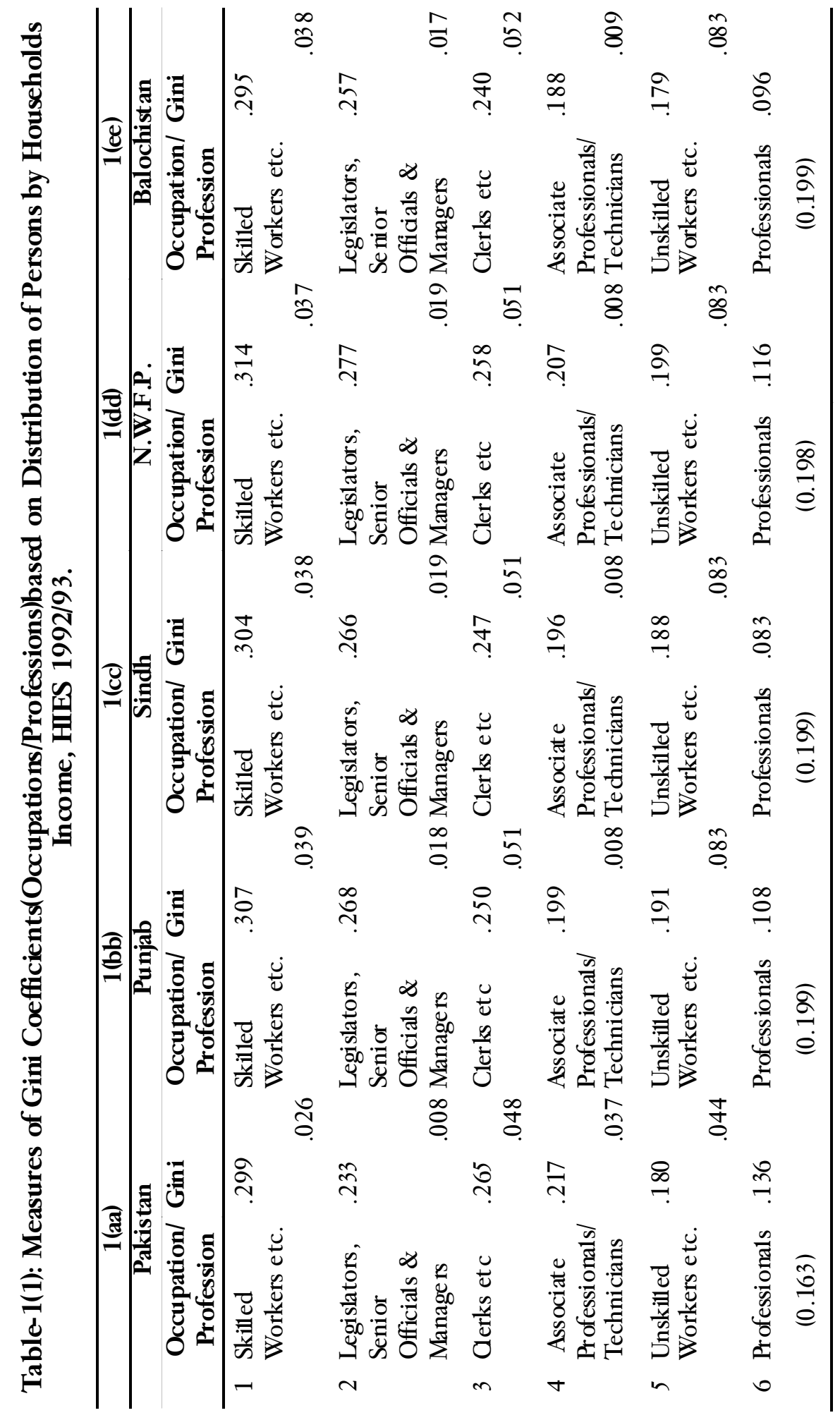




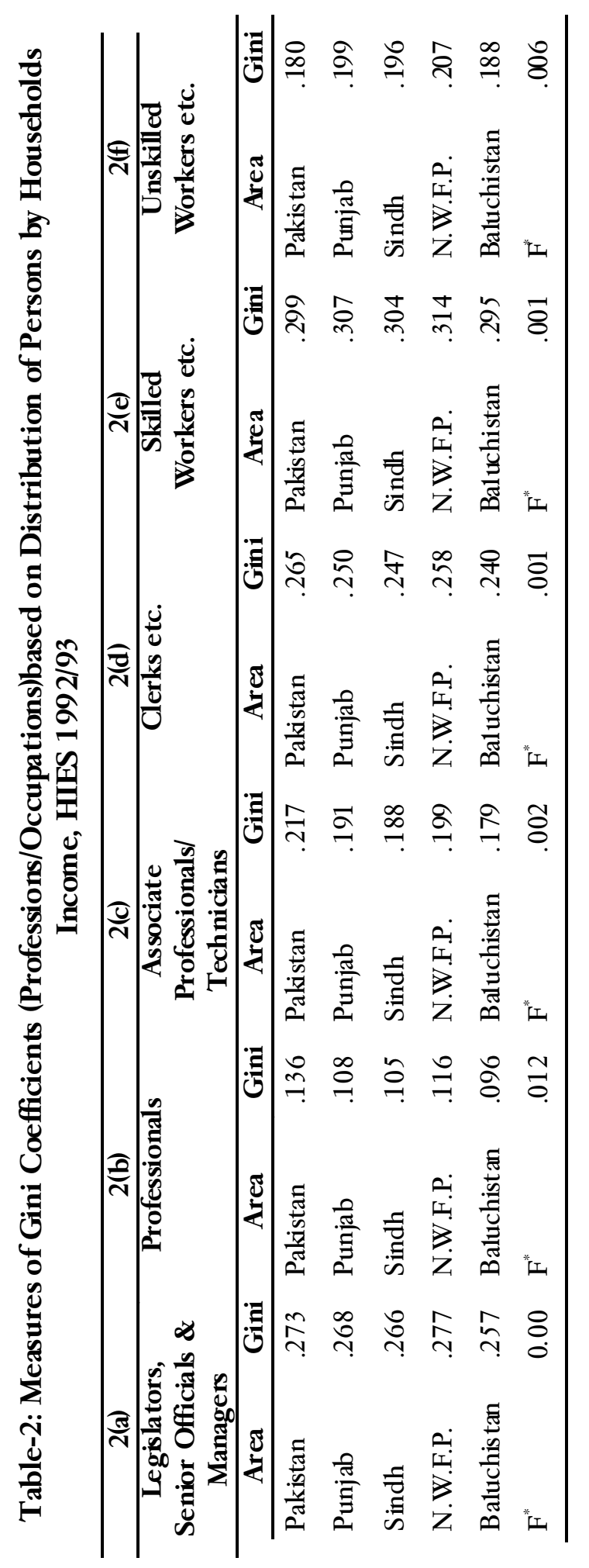


102 The Lahore Journal of Economics, Vol.7, No.1

\section{Conclusions}

Finally the following conclusions are submitted:

1. Within various occupations/professions in Pakistan, the highest level of inequality is observed among skilled workers and lowest level of inequality is seen among professionals.

2. The level of inequality among skilled workers is slightly higher than overall inequality in Pakistan and level of inequality among professionals is much lower than the national inequality.

3. A similar pattern is observed within all the provinces of Pakistan.

4. The relative inequality among occupations/ professions is the same in all the provinces of Pakistan.

5. Within various occupations/professions, the lowest level of inequality is observed in the province of Balochistan and highest level of inequality is seen in the province of N.W.F.P. In other words all occupations/professions in Balochistan exhibit lowest inequality among its ranks and all occupations/professions in the N.W.F.P. show the highest level of inequality among its members.

6. The data is interpreted on the basis of an informed guess but very close to the realities of our country. For example, our data suggests that rulers (legislators etc.) of our country are one class and this fact has been written about in various newspapers. 


\section{References}

Ahmad, Ehtisham and Ludlow, Stephen, 1989, Poverty, Inequality and Growth in Pakistan. The Pakistan Development Review, Vol.28, No.4, PP. 831-850.

Amjad, R., 1977, Concentration and Profitability in Pakistan, JDS. Vo1. 13, No.3, April 1977.

Ayub, M.A., 1984, Sources and Structure of Income Inequality in Pakistan, Paper presented at The Second Annual General Meeting of Pakistan Society of Development Economists, Islamabad.

Bergan, Asbjorn, 1967, Personal Income Distribution and Personal Savings in Pakistan, 1963/64. The Pakistan Development Review, Vol.7 No.2.

Cheema A.A., 1986, Poverty in Pakistan: Some New Dimensions, unpublished paper, PIDE, Islamabad.

Cheema, A.A. and Malik, M.H. 1984, Consumption and Employment Effects of Income Redistribution in Pakistan. The Pakistan Development Review. $23(2 \&$ 3), P.P. 347-360.

Choudhary, M.K. 1995, National and Provincial Size Distribution of Income in Pakistan, Journal of Economics Vol. 2 Sep. 1995.

Choudhary, M.K. 1982, Foreign Aid and Economic Development: A Case Study of Pakistan with Special Reference to Poverty and Income Distribution, Unpublished Ph.D. Thesis, submitted to the University of Salford.

Choudhry M. Ghaffar, 1982, Green Revolution and Redistribution of Rural Income: Pakistan Experience. The Pakistan Development Review Vol.21, No.3.

Choudhry, M.K., 1984, Income Inequality in Pakistan-Some Estimates Based on Household Income Per Capita The Kashmir Economic Review, Vol.1, No.2.

Choudhry, M.K., 1984, The Statistical Evidence on Income Inequality in Pakistan - Some Observations, The Kashmir Economic Review, Vol.1 No.1. 
104 The Lahore Journal of Economics, Vol.7, No.1

Datta, G. and Meerman, J., 1980, Household Income or Household Income Per Capita in Welfare Comparisons, Review of Income and Wealth, Series No.26.

Ercelawn, A., 1988, Income Inequality in Pakistan During the 70s: Issues in Estimation. Discussion Paper No.92. Karachi, Applied Economics Research Center, Karachi.

Henry, R.M., 1975, A Note on Income Distribution and Poverty in Trinidad and Tobago, Research Working Paper WEP 2-23/WP 29 Geneva, ILO.

HIES, 1992/93, Federal Bureaus of Statistics, Statistic Division, Govt. of Pakistan.

Hsia, R. and Chau, L., 1978, Industrialisation, Employment and Income Distribution: A Case Study of Hong Kong . A study prepared for ILO London Croom Helm.

Hussain, A., 1992, Poverty and Poverty Alleviation, Paper presented to Pakistan Institutte of Development Economics and Planning Commission of Pakistan, as an input into 8th Five Year Plan 1993-98.

Iqba1, M. Qamar, 1988, Use of Inequality Measures in Calculating Income Elasticity, The Pakistan Journal of Applied Economics, Vo1. 7, No.1.

Jafari, S. Y. and Khattak Azizullah, 1995, Income Inequality and Poverty in Pakistan, Pakistan Economic and Social Review Vol. XXXIII No 1 and 2.

Jeetun, A., 1981, Trends in Inequality of Income Distribution in Pakistan. Discussion Paper No.29. Applied Economic Research Center, University of Karachi.

Kakwani, N., 1980, Income Inequality and Poverty: Method of Estimation and Policy Application, N. Y. Oxford University Press.

Kakwani, N. 1980, Income Inequality and Poverty: Method of Estimation and Policy Application, N. Y. Oxford University Press.

Kemal, A.R., 1981, Income Distribution in Pakistan: A Review. Research Reports Series No.123. Pakistan Institute of Development Economics, Islamabad. 
Kemal, A.R., 1994, Structural Adjustment, Employment, Income Distribution and Poverty. The Pakistan Development Review 33(4), 901-911.

Khadija Haq, 1964, A Measurement of Inequality in Urban Personal Income Distribution in Pakistan, The Pakistan Development Review, 4(4), Winter 1964.

Khan, M.F., 1990, Factors of Production and Factor Markets in Islamic Framework, Journal of King Abdul Aziz University: Islamic Economics, vol.2, 1410/1990.

Kondor Yaakov, 1975, The Gini Coefficients of Concentration and the Kuznets Measure of Inequality. A note Review of Income and Wealth series 21 No.3 Sept 1975.

Koutsoyiannis, A. - Theory of Econometrics. 2nd ed.

Kruijk de Hans, 1986, Inequality in the Four Provinces of Pakistan. The Pakistan Development Review Vol.25 No.4.

Kruijk de Hans and Myrna,Van Leeuwen, 1985, Changes in Poverty and Income Inequality in Pakistan During the 1970s The Pakistan Development Review No. 3 and 4.

Kumar, D., 1974, Changes in Income Distribution and Poverty in India: A Review of the Literature. World Development, Vol.2 No.1.

Kuznets, S., 1955, Economic Growth and Income Inequality, American Economic Review, March.

Kuznets, S., 1963, Quantitative Aspects of Economic Growth of Nations: Distribution of Income by Size, Economic Development and Cultural Change Vo1.II , 1963.

Kuznets, S., 1976, Demographic Aspects of the Size Distribution of Income: An Exploratory Essay, Economic Development and Cultural Change. Vo1. 25, No.1, October

Mahmood, Zafar, 1984, Income Inequality in Pakistan: An Analysis of Existing Evidence. The Pakistan Development Review, Vol.XXIII, Nos. $2 \& 3$ (Summer Autumn 1984). 
106 The Lahore Journal of Economics, Vol.7, No.1

Morgan, James, 1962, The Analogy of Income Distribution Review of Income \& Statistics vo1.XLIO No.3 Aug. 1962.

Mujahid, G. B .S., 1978, A Note on Measurement of Poverty and Income Inequalities in Pakistan: Some Observations on Methodology. The Pakistan Development Review 17(3).

Ojha. P.D., 1971, Pattern of Income Distribution in India, 1953-55 to 1961-64, (Mimeographed).

Pakistan Economic Survey 1999.

Visaria, P., 1978, Demographic Factors and the Distribution of Income, Some Issues, Paper prepared for the Conference on Demographic and Economic Change: Issues for the 1980s, Convened by the International union for the Scientific Study of Population, Helsinki, August 28-September 1.

Yotopoulos, Pan, 1987, A. The 'World' Distribution of Income and Real Poverty and Affluence Pakistan Development Review, Vo1. XXVI, No.3, Autumn 1987. 